\title{
AIR QUALITY, URBAN FLUXES AND CITIES RESILIENCE UNDER CLIMATE CHANGE - A BRIEF OVERVIEW
}

\author{
CARLOS BORREGO, SANDRA RAFAEL, VERA RODRIGUES, ALEXANDRA MONTEIRO, SANDRA \\ SORTE, SÍLVIA COELHO \& MYRIAM LOPES \\ CESAM, Department of Environment and Planning, University of Aveiro, Portugal
}

\begin{abstract}
Cities are home of about $70 \%$ of the European population, and it is expected that by 2050 this number will be achieved around the world. As a result, cities are facing important challenges related to pressures induced by changes on urban metabolism and by climate change (CC) effects. Understanding the key factors determining the vulnerability of a city provides a framework to consider resilience. These issues become more and more relevant since changes in urban structure and metabolism together with CC will start affecting atmospheric emissions, urban air quality and consequently human health. Cobenefits of an urban air quality and CC approach need to be further addressed taking into consideration that CC creates both risks and opportunities. Therefore, an integrated assessment of the interaction between resilience factors and CC effects, and its influence on the urban microclimate and air quality, is required to better adapt to future climate. This knowledge is fundamental to support policy makers and stakeholders helping them to choose the best strategies to manage resources, to mitigate extreme weather events and to predict air pollution episodes. This article offers a systematic review on CC impacts in cities, providing some adaptation strategies and suggesting future research topics.

Keywords: air quality, cities, climate change, cobenefits, energy fluxes, resilience, weather patterns
\end{abstract}

\section{INTRODUCTION}

The effects of urbanization and climate change (CC) are converging in a critical way. Cities are major contributors to CC, although they cover less than $2 \%$ of earth's surface, since they consume $78 \%$ of the world's energy and produce more than $60 \%$ of all carbon dioxide and significant amounts of other greenhouse gas emissions [1-5]. At the same time, cities and towns are highly vulnerable to $\mathrm{CC}$ due to the high population density and diversity, complexity of the built environment and dependence on the technological systems for survival. In addition, over $90 \%$ of all urban areas are coastal areas, and therefore are prone to flooding due to both rise in sea level and changes and intensity of storms [6]. Moreover, the majority of the vital economic and social infrastructures, government facilities and assets are located in cities, then $\mathrm{CC}$ affects negatively all the urban infrastructures threatening the so far guaranteed access to basic urban services and quality of life [7]. Furthermore, in the last two decades, population health is becoming more and more threatened by extreme weather events in urban areas [8].

Urban land use and urban sprawl can influence local meteorology [9], atmospheric emissions and pollutant concentrations, as well as the water and energy fluxes [10]. As a result of high population density, cities tend to have a high fraction of impervious cover and a low fraction of green spaces. Green areas represent a determinant key of the energy balance [6]. In addition to the physical nature of the built environment, people's behaviour, i.e. how they live, work, move from a place to another etc., influences the weather patterns and climate variability $[11,12]$.

Related to the need of cities adaptation to $\mathrm{CC}$ effects, the concept of resilience has arisen, defined as the capacity of a system to absorb disturbance and re-organize while undergoing change so as to still retain essentially the same function [13]. Resilience is directly related 
to city vulnerability to urban climate effects and to weather extreme events. Increase urban resilience is widely cited in the European Climate Policy as a key target in adaptation and mitigation strategies. Besides, it is mentioned that the nature-based solutions and renaturation of cities put forward the development of methodologies on 'Innovating with Nature' areas, making more sustainable and resilient societies. These so-called nature-based solutions provide sustainable responses, low-cost, multi-purpose and flexible alternatives to face CC impacts. Using nature solutions helps to promote a sustainable use of resources and to achieve an efficient, competitive and greener economy. Nature-based solutions also support the establishment of new jobs, through the production and supply of new products and services that increase the natural capital rather than exhausting it.

A better understanding of the changes in urban structures and metabolism combined with $\mathrm{CC}$ and their effects on atmospheric emissions, urban air quality- and health-related issues, has encouraged a widespread range of multidisciplinary research in the last decades [2]. An integrated assessment of the interactions between resilience factors and CC effects, and their influence on urban microclimate and air quality is crucial to better adapt urban areas to future climate. A throughout evaluation of resilience measures effectiveness requires accurate measurements, physical and numerical models.

The main purpose of this article is to compile conceptual issues concerning CC in cities focusing on essential areas that have been investigated around the world. These research lines, owing to its relevance to urban sustainability and human health, still requires further attention by the world research community.

\section{CLIMATE CHANGE IN CITIES}

\subsection{Impacts of CC}

According to the recent Intergovernmental Panel on Climate Change (IPCC) 5th Assessment Report [14], warming of the climate system is unequivocal. The atmosphere and ocean have warmed, the amounts of snow and ice have diminished and the sea level has risen. The past three decades have been successively warmer at the earth's surface than any preceding decades since 1850 and surface temperature is projected to rise over the 21 st century under all assessed emission scenarios.

Surface temperature increase depends on three main factors: (i) the level of stabilization of carbon emissions, (ii) the pace of de-carbonization of the global economy and (iii) the patterns of demographic and economic development [14]. The nature of the built environment, structural aspects such as streets, buildings and infrastructures, modify significantly the emission of GHGs and amplify CC impacts $[6,15]$. Without significant changes in policy, the trend in global emissions of GHGs and associated CC will continue. These changes will lead to wide-ranging impacts and economic costs across different sectors and regions. At the same time, there is an increasing recognition of the potential impacts of CC in cities [16].

According to Revi et al. [17], urbanization alters local environments via a series of physical phenomena that can result in local environmental stresses and pressures. These include urban heat islands (UHI) and local flooding that can be exacerbated by CC. It is critical to understand the interplay among the urbanization process, current local environmental change and accelerating CC. CC can influence this microclimate and localized regional climate dynamics. The majority of studies undertaken to date have identified a set of potential impacts of CC in cities. A review of these impacts can be found in [17]. Their consensus conclusions are that the most important effects of CC on cities are likely to be: (i) sea level rising on coastal cities; 
(ii) issues related to water availability and resources (i.e. energy); (iii) extreme events on built infrastructures; and (iv) higher average temperature and extreme events on health. In the next sections, the main impacts of CC on the urban microclimate and air quality are described.

\subsubsection{Impacts of CC on energy fluxes}

A recent key issue for urban investigations is related with the understanding of how energy in the form of radiation and heat (energy fluxes) influences the urban climate, as well as, in the understanding of how urban geometry, the properties of urban materials, the anthropogenic heat and the presence of vegetation influence the magnitude and the behaviour of these fluxes [18]. These factors are well known as the main contributors to urban heat island formation and to the increment of the heat waves intensity [19]. This information has to be known to address the challenges of urban planning and sustainability, for example, to the management of resources, mitigation and adaptation to CC or air pollution/air quality [18]. Additionally, the understanding and the study of the energy fluxes could be used as a tool to evaluate the occurrence of extreme episodes, heat or cool waves, due to the link between the way in which occur the energy exchanges among the surface and the atmosphere and its influence at the local climate system.

Although the growing interest in urban energy fluxes associated with the importance of urban areas, and the existence of a set of models, which allows the estimation of their magnitude, still few studies have investigated the influence of $\mathrm{CC}$ in the behaviour and magnitude of these fluxes. Wild et al. [20] examined the flux changes in global climate model simulations with increased levels of greenhouse gases and related them to the systematic errors found in the simulation under a current climate. Sheng et al. [21] identified regions with strong changes in climatic variables and surface energy fluxes through identification of their long-term trends and inter-annual variability from 1948 to 2000. Lindberg et al. [1] used LUCY to assess changes in anthropogenic heat flux over a 20-year period (1995-2015) across Europe. Ma et al. [22] estimate the heat flux changes caused by the projected land transformation over the next 40 years across China to improve the understanding of the impacts of land dynamics on regional climate. Rafael et al. [23] analysed the influence of the change of the meteorological variables due to CC (for a medium-term climate considering the Representative Concentration Pathways - RCP8.5 scenario) in the surface energy balance, for the greater Porto urban area (Portugal). The most important conclusions of these works can be systemized as follows: (i) decrease in the latent heat flux, through a reduction in the evaporation rate and so a reduction in the water released to the atmosphere; this will imply a reduction in the global mean precipitation [16, 21]; (ii) increase in the sensible heat flux, which will lead to an atmosphere warm and dry, as well as, to an increase in the globally averaged surface temperature [23]; (iii) increase in the storage heat flux, which could increase surface air temperature at night and decrease the diurnal temperature range; and (iv) changes in air temperature (either by its increase or decrease) will have an impact on the energy consumption, either through heating or cooling, and consequently will affect the behaviour and magnitude of $Q_{\mathrm{F}}$ (anthropogenic heat flow).

\subsubsection{Impacts of CC on air quality}

Extreme weather events have remarkable impacts on air quality degradation from global to local scale [24]. Despite some improvements promoted by the establishment of progressively stricter emission standards for atmospheric pollutants, several world cities, particularly densely populated urban areas, are currently facing air pollution episodes, with frequent 
exceedances to legislated air quality levels. The major air pollutants problems are associated with ozone $\left(\mathrm{O}_{3}\right)$, nitrogen dioxide $\left(\mathrm{NO}_{2}\right)$ and particulate matter $(\mathrm{PM})$ exceedances, thus several air quality assessment studies have been carried out to identify the main causes and to support the design of mitigation plans [9]. In Portugal, over the past few years, air quality records point out several exceedances to the legal limit values, in terms of $\mathrm{O}_{3}$ [25], $\mathrm{NO}_{2}$ [26] and PM [27] concentrations, mainly over two main regions, the Lisboa e Vale do Tejo region and the Northern region. The annual mean of PM10 and $\mathrm{NO}_{2}$ was surpassed in Portugal. There were also an important number of exceedances regarding the $\mathrm{O}_{3}$ target in several air quality stations over the country.

Changes in future climate will affect future air quality patterns since air pollutants dispersion is highly driven by climate-related events [28]. Meteorology plays a major role in air pollutants formation, dispersion, transport and dilution, then changes on local meteorology conditions, i.e. wind speed and direction, temperature and humidity, may affect the time and spatial distribution of air pollutants [29]. In particular, climate variability may induce changes in the chemical transformation process, that is, in the boundary layer depth, which directly affect pollutants vertical mixing, and in synoptic circulation, which influence pollutants transport [30]. These changes will affect the concentrations and dispersion of air pollutants, consequently increasing the magnitude and frequency of air pollution episodes. Furthermore, climate-driven changes in meteorology may also modify the natural emissions patterns. Besides, CC will also affect human activities, leading to an impact over the anthropogenic emissions. Future projections of air quality patterns need to take into account changes in both future climate and future emission scenarios, in terms of primary atmospheric pollutants and the precursors of secondary pollutants, due to their closely coupled impacts on air quality [31].

The interaction between CC, atmospheric pollutant emissions and concentrations is still an utmost challenge under research requiring urgent progress in order to understand and to predict accurately the changes in air pollutant levels, affecting regional and urban air quality patterns, in future climate scenarios at different spatial and time scales. The vast majority of studies assessing the impacts of $\mathrm{CC}$ on air quality patterns are focused on $\mathrm{O}_{3}$ [32]. Despite the relevance of an improved knowledge about surface PM concentration sensitivity under CC, only a few studies have been conducted. Carvalho et al. [33] found that throughout Portugal the maximum increase in PM10 concentrations are foreseen for the northern coastal region. Recently, Sá et al. [34] have shown evidences regarding the increase in extreme values for $\mathrm{O}_{3}$ and PM10 concentrations under future climate, in 2050. Considering only CC effects, $\mathrm{NO}_{2}$ and PM10 annual average concentrations will increase in Portugal and in Porto urban area, while $\mathrm{O}_{3}$ concentrations will increase in suburban areas and decrease in urban areas. On the other hand, considering also projected anthropogenic emissions combined with climate effects, $\mathrm{NO}_{2}$ annual average concentrations will significantly decrease in Portugal and over Porto urban area, mainly due to the reduction in the projected emissions (accordingly to the IPCC projections). In this case, PM10 annual average concentrations will increase over Portugal and reduce over Porto urban area, while $\mathrm{O}_{3}$ concentrations will increase in the surrounding areas and decrease within urban areas, mainly due to the reduction of $\mathrm{O}_{3}$ precursors. Sá et al. [34] indicate that for Porto urban area PM10 and $\mathrm{O}_{3}$ concentrations will record increases in occurrences, duration and intensity of extreme values, surpassing the annual legislated values, recording a higher number of daily exceedances. This air quality degradation pattern is likely related with the trends found for future climate, which implies warmer and dryer conditions, followed by an increase in background concentrations of $\mathrm{O}_{3}$ and PM10. 


\subsection{Assessment of CC impacts}

Numerical models have emerged as a useful and powerful tool to understand and assess the physical and chemical processes of the atmosphere at local, regional and global scales. The capability to study different areas at different scales (resolution, a key issue to approach the scientific results to the persons in streets) and the ability to study multi-pollutant and multiyear integrated analysis (i.e., long-term simulations for different scenarios) are highly advantageous characteristics for policy makers and stakeholders' decision making.

Projections of changes in the climate system are made using a hierarchy of climate models ranging from simple climate models, models of intermediate complexity, comprehensive climate models and Earth System Models (ESMs). These models simulate changes based on a set of scenarios of anthropogenic forcing. A new set of scenarios, the representative concentration pathways (RCPs), was described in 5th IPCC Assessment Report [14]. Global climate models (GCM) has been used to study the impact of anthropogenic emission of GHG effect on global CC scenarios. Although it is important to understand global trends and $\mathrm{CC}$ behaviour, its low spatial resolution cannot resolve meso- to local-scale phenomena. Therefore, to assess the impact of CC at a local scale, regional CC modelling is needed. Regional climate models (RCMs) need initial and boundary conditions set by GCMs to produce results. RCMs do not change the large-scale atmospheric circulation of GCMs, while adding regional detail in response to the large-scale forcing, simulating more realistically surface winds and temperatures over complex terrain and coastlines, as well as mesoscale processes and its variability. A highly detailed and accurate model solution over the region of interest is then achieved [35]. Each step of projecting climatic variables includes uncertainties, but by choosing more than one emission scenario, working with an ensemble of GCMs and using different techniques to obtain regional projections, we could minimize these uncertainties to levels that enable us to use the projections to identify consequences of climate impacts and needed adaptations [36].

The assessment of future air quality patterns can be performed considering the effect of future climate, keeping pollutant emission scenarios constant [37]; considering the changes on the pollutant emission scenarios and maintaining the meteorological conditions constant [38]; and considering both the effects of $\mathrm{CC}$ and the modification of the pollutant emissions in future scenarios [32]. Concerning the future emission scenarios, most of the studies performed so far take into account the future-year simulation based on the IPCC RCP scenarios. In urban areas, this assessment can be performed using high-resolution models. In the last two decades, the characterization of the atmospheric turbulent flow and the pollutants dispersion in urban areas has been performed using physical models such as wind-tunnels [39], experimental campaigns [40] and numerical models [41]. The continuous improvement of computational resources capacities has supported the development of more and more complex numerical models followed by a noteworthy increase in the number of numerical studies of the turbulent flow dynamics and pollutants dispersion in highly complex urban areas. Currently, there is a wide range of numerical models available with distinct levels of complexity suitable for the evaluation of the urban microclimate, including the energy fluxes exchanges and the pollutants dispersion, allowing to determine air quality patterns in highly complex urban areas. Different models can be used to investigate air quality at different spatial (at urban, local and microscale) and temporal scales (ranging from seconds to a few hours), each one of them with distinct advantages and disadvantages. In particular, the computational fluid dynamics (CFD) models have been used to compute the turbulent flow dynamics and the atmospheric 
pollutants dispersion within the urban surface layer. These models allow taking into account the morphological complexity specificities of the urban environment, and consequently, they are able to simulate the flow dynamics perturbations caused by distinct urban obstacles. Recent reviews on the numerical modelling of the flow dynamics and the passive tracer dispersion in urban areas using CFD models are presented by Lateb et al. [42].

In terms of representation of urban surface energy balance in mesoscale models, there has been an explosion of development over the last decade [43]. This has been a result of the need of better resolve the atmospheric process at the urban scale on numerical weather and air quality models. The recent International Urban Energy Balance Comparison Project [44] was a collective effort to compare modelled fluxes using 32 different surface schemes with highquality measured data. The project concluded with two main aspects: (i) no single model had the best performance across all fluxes and (ii) the results were highly sensitive to the quality of the input (i.e. thermal characteristics of urban materials and morphology of buildings), which is often difficult to obtain. In this sense, the importance of accurate representation of vegetation was highlighted in simulating correct portioning of the turbulent fluxes (sensible and latent). This is especially important for modelling urban boundary layer (UBL) dynamics, as growth rate and depth of the UBL is determined primarily by the sensible heat flux.

Different models can be used to investigate urban energy balance fluxes, each one of them with different advantage/disadvantages and with different applicability. Examples of these models are (i) Advanced Canopy-Atmosphere-Soil Algorithm (ACASA) [45] developed by University of California, which is a multilayer model that extends to $100 \mathrm{~m}$ above the canopy elements to ensure applicability of the turbulence assumptions; the model uses mass conservation with the absorbed available energy partitioned into sensible and latent heat flux; (ii) Surface Urban Energy and Water Balance Scheme (SUEWS) [11], which allows both energy and water balances at urban scale to be calculated; (iii) Town Energy Balance (TEB) [46], which simulates the energy and water exchanges between the city and the atmosphere; and (iv) Large-scale Urban Consumption of Energy (LUCY) [1], which estimates the anthropogenic heat flux and its spatial and temporal distribution.

\section{COBENEFITS BETWEEN GLOBAL CLIMATE CHANGE AND URBAN POLLUTION}

Pollutants emitted by human activities have caused declines in air quality and drastic changes to climate. Despite being inextricably linked, these two major environmental issues tend to be viewed separately by policy (in the EU, air quality and climate change are dealt with by separate policy frameworks in different Directorates General: DG Environment (air quality) and DG Climate Action (CC)). However, in certain instances, considering these issues together could lead to strategies that benefit both [47]. These challenges are connected in many ways, and it is impossible to separate emissions into clear groups of air borne pollutants and climate forcers, as most emissions have effects on both.

Air quality and climate policies can provide mutual benefits: $\mathrm{CC}$ mitigation actions can help reduce air pollution, and clean air measures can help reduce GHG emissions leading to reductions in global warming. There can also be trade-offs, if reducing a particular pollutant emission leads to additional atmospheric warming rather than cooling. Furthermore, air pollution and $\mathrm{CC}$ influence each other through complex interactions in the atmosphere. Recent research studies investigate the trade-offs and cobenefits that may be gained from reducing both long-lived GHGs, responsible for CC and air pollutants, with impacts on human health, ecosystems and the climate [48]. 
According to several authors, PM is the atmospheric component that best illustrates the air quality-climate change connection. The overall impacts of reductions are complex because PM is made up of many different chemical components with different physical properties, some of which lead to warming of temperatures (i.e. black carbon) by absorbing heat from the sun, while others (i.e. sulphates) bring about cooling effects by reflecting sunlight. Emission control policies to improve air quality, by reducing PM10, for example, could reduce the number of premature deaths due to air pollution but increase future climate warming. This is an example of a mitigation option that benefits one side (air pollution) but may worsen the situation in another (climate) [49]. However, there are mitigation options related to PM that could improve both [50]. Adequate black carbon control measures would therefore have multiple benefits [51]. Ground-level O3 is also a serious pollutant, which at high levels, damages human health and vegetation, including crop yields. In addition, $\mathrm{O}_{3}$ is a short-lived GHG contributing to $\mathrm{CC}$. Policies and management strategies to reduce $\mathrm{O}_{3}$ levels must be designed in the light of evidence that there is a 'climate penalty' since increased temperatures make it more difficult to reach targets for $\mathrm{O}_{3}$ in summertime.

Andersson and Engardt [52] compared the costs and benefits of implementing reductions in local air pollution and CC actions separately or in combination. The message, again, is that simultaneous achievements in welfare and $\mathrm{CC}$ are possible when decision-makers integrate both sets of policies. Bollen et al. [53] compared the costs and benefits of separate strategies for global CC mitigation and reductions in local air pollution (LAP), in addition to the impacts from combining these two sets of policies. Benefits of LAP policy focused on avoided early deaths from long-term exposure to PM pollution produced by fossil fuel combustion, while benefits of CC policy focused on the avoided loss of GDP as a result of $\mathrm{CO}_{2}$ emissions. Overall, the study found that environmental policies that mitigate $\mathrm{CO}_{2}$ emissions and PM pollution, either alone or combined, provide greater benefits than the costs of the policies. Nemet et al. [54] presented an analysis of the barriers and opportunities for incorporating air quality cobenefits into climate policy assessments. In a survey of previous studies, they found a range of estimates for the air quality cobenefits of $\mathrm{CC}$ mitigation of $\$ 2-196 / \mathrm{CO}_{2}$ with a mean of $\$ 49 / \mathrm{CO}_{2}$ and the highest cobenefits found in developing countries. These values, although of a similar order of magnitude to abatement cost estimates, are only rarely included in integrated assessments of climate policy. Full inclusion of these cobenefits would have pervasive implications for climate policy in areas including: optimal policy stringency, overall costs, distributional effects, robustness to discount rates, incentives for international cooperation and the value of adaptation, forests, and climate engineering relative to mitigation. Because policy debates are framed in terms of cost minimization, policy makers are unlikely to fully value air quality cobenefits unless they can be compared on an equivalent basis with the benefits of avoided climatic damages. While air quality cobenefits have been prominently portrayed as a hedge against uncertainty in the benefits of $\mathrm{CC}$ abatement, this assessment finds that full inclusion of cobenefits depends on better valuation of climate damages.

Ongoing research can provide opportunities for decision-makers to choose policies that not only reduce GHGs but improve air quality and meet health goals [34]. And these potential additional benefits can be an extra incentive for countries to participate in a future climate agreement. Integrated assessment modelling techniques, for example, are used to identify the cobenefits of combined air pollution and CC mitigation strategies [55]. These techniques can help to avoid trade-offs, for example where increased use of biomass for residential heating reduces carbon footprint but contributes to PM emissions. It is important that future policies 
avoid these adverse effects and maximize the cobenefits. Pursuing optimal policies will require careful management and political cooperation. An example was the European Directive that implemented Euro 5 and 6 light-duty vehicle emissions standards, which required the use of diesel particulate filters, and which led to a small increase in fuel consumption (and therefore $\mathrm{CO}_{2}$ emissions) which was met with some concern by the climate community. Similar negotiations will become increasingly important in the future.

\section{CITIES RESILIENCE TO CLIMATE CHANGE}

\subsection{Examples of resilience measures}

The notion of resilience is gaining increasing prominence across a diverse set of literatures on cities and CC [1]. The knowledge acquired in the last decades related to the strategies to adapt urban areas or to improve their adaptive capacity, provided the tools for the development of a resilience framework for decision-makers understand how their cities are able to respond to the impacts of $\mathrm{CC}$ and thereby identify the most critical vulnerabilities and the measures to enhance its natural property. An urban resilience framework can be obtained through the use of basic principles of decision-making and vulnerability analysis in order to answer two questions: What are the climate vulnerabilities that may affect the decisions to be taken? What are the measures needed to increase the resilience and when they should be implemented [15]?

The main expected impacts of $\mathrm{CC}$ in cities are related to increasing temperature and its extreme events and to air quality degradation; therefore, the selection of resilience measures should aim to mitigate these impacts. There is growing recognition and awareness that nature can help provide viable solutions that use and deploy the properties of natural ecosystems and the services that they provide in a smart, 'engineered' way. These nature-based solutions provide sustainable, cost-effective, multi-purpose and flexible alternatives for a set of goals. Working with nature, rather than against it, can further pave the way towards a more resource-efficient, competitive and greener economy. It can also help create new jobs and economic growth, through the manufacture and delivery of new products and services, which enhance the natural capital rather than deplete it. Nature-based solutions have been widely applied in European cities with interesting results [2]. The most reported strategy related with the nature-based solution is the integrating grey with green and blue infrastructure, such as green walls and roofs, urban brownfields, social agriculture and biomimicry - innovation inspired by nature and novel design [56].

\subsection{Assessment of resilience measures in cities}

Adaptation strategies to $\mathrm{CC}$ have the potential to increase resilience of urban areas to extreme weather events. An improved knowledge about the highly complex urban microclimate is thus of extreme importance to circumvent $\mathrm{CC}$ impacts at urban scale, either by assisting on the design of efficient resilience measures or by allowing a more insightful topological organization of novel urban areas. An improved understanding of the urban microclimate requires accurate measurements, physical and numerical modelling of the turbulent exchanges between surface, urban canopy and atmosphere, which strongly depend on the characteristics of the UBL [57].

Currently, there are a wide range of numerical models with distinct levels of complexity and with different research focus, as discussed in Section 2.2. Numerical simulations using 
CFD models at local scale have been performed to assess the effect of a set of resilience measures on temperature during a heat wave [58]. Physical models, like wind tunnels, have been used to study the atmospheric flow dynamics around obstacles and the pollutants dispersion patterns within complex urban environments. Wind-tunnel simulation outputs allow the identification of the main causes of poor air quality in urban areas and the assessment of distinct resilience factors [59]. On the basis of the comparison between different future planning scenarios, it is possible to determine the effectiveness of the selected resilience measures. Both modelling tools and physical simulation, such as wind-tunnel experiments, represent the ultimate framework to assess the effectiveness of distinct resilience measures. Through the development of a set of future scenarios, numerical and physical simulations allow the evaluation of distinct resilience measures. The assessment of the effectiveness of a set of resilience measures provides to policy makers and stakeholders the needed data to select the most adequate measures in order to better adapt to $\mathrm{CC}$.

\subsection{Expected impacts of resilience measures in future climate scenarios}

Several studies have been conducted to assess the influence of resilience measures, in meteorology and air quality. In this section, the expected impacts of three different resilience measures (individually and combined together) are presented: (i) increase in green urban areas; (ii) application of green roofs; (iii) application of white roofs; (iv) increase in green urban areas plus application of green roofs; and (v) increase in green urban areas plus application of white roofs. The effectiveness of these measures will be assessed regarding the impacts on meteorology and on heat fluxes, for an extreme event, specifically a heat wave, in a medium-term future climate (2050). Studies performed with a high spatial resolution were analysed. Carvalho et al. [60] investigate the effects of the selected resilience factors on the surface temperature fields (mean and maximum), through the differences between a control simulation (without the application of resilience measures) and the different tested resilience measures. Carvalho et al. [60] show that the increase in green urban areas scenario produces a reduction on the mean and maximum temperatures, due to an increase in the surface moisture availability and a local cooling associated with evapotranspiration. However, these temperature differences are mostly located in the vicinity of the added green urban areas. This study clearly shows that increasing green roofs coverage will progressively reduce the surface temperatures. Regarding the application of white roofs as a resilience measure, Carvalho et al. [60] present a lower reduction on the urban temperature than the green roofs scenario. The application of green roofs, alone or combined with the increase in urban green areas, is the more effective scenario for the maximum temperature. In addition, the effectiveness of the resilience factors is more evident for thermal comfort of the urban population in the maximum temperature, which is up to $1^{\circ} \mathrm{C}$.

Furthermore, the large-scale application of the proposed resilience measures will significantly contribute for the mitigation of air pollution. On the one side, the lower-energy requirements for cooling will lead to lower emissions of $\mathrm{CO}_{2}$, NOx and particulate matter produced by electrical power plants. On the other side, the increase in urban green areas and application of vegetated roofs will lead to the conversion of $\mathrm{CO}_{2}$ into $\mathrm{O}_{2}$ due to photosynthesis. Furthermore, the production of hazardous urban ozone smog and its precursors is promoted by high-temperature records then lower urban temperatures will mitigate this ozone production.

Rafael et al. [2] performed a study where the influence of green urban areas and application of white roofs to the components of the energy balance were assessed. The following 
conclusions were obtained: (i) the increase in green urban areas promotes an increase in the magnitude of the latent heat flux, which is result of the increase in the evaporation process; (ii) more latent heat flux means that a higher proportion of solar radiation is used in the evaporative process, thereby a reduction in sensible heat flux is obtained contributing to a reduction in the energy released into the atmosphere and for the cooling of the surface; (iii) the introduction of white roofs implies that less solar radiation is absorbed by the surfaces, which promotes a reduction of the sensible and storage heat flux, contributing also to a reduction in the surface temperature.

\section{FORTHCOMING RESEARCH}

The current projections of urban population, in particularly its continuous growth, will determine the forthcoming research. The full understand of the links between CC and different sectors (air quality, ecosystems, human health, energy and water management), will be the challenges of the future research. It is vitally important for our cities to function efficiently in the future, and therefore, a set of key policies and initiatives should be taken, namely related to the: (i) creation of mechanisms for prevention, detection, alert and management the risks of extreme weather events; this should include preparedness of citizens, institutions and systems; (ii) development of tools to quantify the costs related to material and human damages caused by extreme weather events, and develop financial/economic mechanisms for adaptation, restoration and compensation of such damages; (iii) better understanding of CC impacts on urban supply systems and infrastructures (energy, electricity, food, water and sewage, wastes, TIC) and development of strategies and technological solutions to increase the resilience of those systems and guarantee their proper function in order to satisfy future particular human needs; (iv) raise public awareness related with their consumption patterns and the importance of stimulate local economy (i.e. urban agriculture, preference for products and goods produced within the region) as a way to reduce our ecological and carbon footprint; (v) review of urban planning and local policies, including the key aspects of CC going behind the existing tools like Covenant of Mayors and Mayors Adapt in order to achieve a more sustainable city.

In terms of air quality, the research should be focused in following main topics: (i) understand the influence of CC on air pollution due to fine PM, since current assessment of this pollutant still have a set of uncertainties; (ii) understand the interactions in the atmosphere between naturally emitted compounds and new man-made pollutants (related to nanoparticles and nanotechnologies); (iii) identify cobenefits of reducing air pollutants that also reduce the impacts of climate change and promotes the green and low-carbon economy; (iv) developing adaptation measures, from urban to districts and street level, according to each city characteristics (geography, dimension, environmental problems, among others); (v) since $\mathrm{CO}_{2}$ concentrations are expected to continue to increase in the future, it is a priority to assess the impact of high $\mathrm{CO}_{2}$ levels on living organisms and particularly in human health.

To encourage more innovation and research on ways to improve cities resilience to climate change, the European Union should continue to promote the investments on 'smart' cities to pioneer green technologies and to showcase the new generation of buildings and alternative energy sources and increase energy efficiency. Last but not the least, we need to rethink the cities and their focus - cities should serve the citizens more than accommodate them. Putting citizens in the centre of decision, engage them on decision-making process through their active participation and include their vision to shape the cities of the future should be the ultimate challenge. 


\section{ACKNOWLEDGEMENTS}

The authors acknowledge the financial support of CLICURB project (EXCL/AAG-MAA/ 0383/2012), supported in the scope of the European Funds through COMPETE and by National Funds through the Portuguese Science Foundation (FCT) within project PEst-C/ MAR/LA0017/2013. An acknowledgement to the Portuguese 'Ministério da Ciência, Tecnologia e Ensino Superior' for the PhD grant of Sandra Rafael (SFRH/BD/103184/2014).

\section{REFERENCES}

[1] Lindberg, F., Grimmond, C.S.B., Yogeswaran, N., Kotthaus, S. \& Allen, L. Impact of city changes and weather on anthropogenic heat flux in Europe 1995-2015. Urban Climate, 4, pp. 1-15, 2013. DOI: 10.1016/j.uclim.2013.03.002

[2] Rafael, S., et al. Influence of urban resilience measures in the magnitude and behaviour of energy fluxes in the city of Porto (Portugal) under a climate change scenario. Science of the Total Environment, 566-567, pp. 1500-1510, 2016. DOI: 10.1016/j.scitotenv.2016.06.037.

[3] Freeman, R. \& Yearworth, M. Climate change and cities: Problem structuring methods and critical perspectives on low-carbon districts. Energy Research \& Social Science, 25, pp.48-64, 2017. DOI: 10.1016/j.erss.2016.11.009.

[4] Araos, M., et al. Climate change adaptation planning in large cities: A systematic global assessment. Environmental Science \& Policy, 66, pp. 375-382, 2016. DOI: 10.1016/j. envsci.2016.06.009.

[5] Schiavon, M., Antonacci, G., Rada, E., Ragazzi, M. \& Zardi, D. Modeling human exposure to air pollutants in an urban area. Revista De Chimie, 65, pp. 61-64, 2014.

[6] Grimmond, C.S. Urban climate in the coastal zone: Resilience to weather extremes. In Pelling, M. (ed.). Megacities and the Coast: Transformation for Resilience, a preliminary review of knowledge, practice and future, Abingdon: Land-Ocean Interactions in the Coastal Zone (LOICZ), pp. 37-42, 2011.

[7] González, A., Donnelly, A., Jones, M., Chrysoulakis, N. \& Lopes, M. A decision-support system for sustainable urban metabolism in Europe. Environmental Impact Assessment Review, 38, pp. 109-119, 2013. DOI: 10.1016/j.eiar.2012.06.007.

[8] WHO. Global health risks: mortality and burden of disease attributable to selected major risks. Bulletin of the World Health Organization, 87, p. 63, 2009.

[9] Figueiredo, M.L., Monteiro, A., Lopes, M., Ferreira, J. \& Borrego, C. Air quality assessment of Estarreja, an urban industrialized area, in a coastal region of Portugal. Environmental Monitoring and Assessment, 185, pp. 5847-5860, 2013. DOI: 10.1007/ s10661-012-2989-y.

[10] Borrego, C., et al. How urban structure can affect city sustainability from an air quality perspective. Environmental Modelling \& Software, 21, pp. 461-467, 2006. DOI: 10.1016/j.envsoft.2004.07.009.

[11] Järvi, L., Grimmond, C.S.B. \& Christen, A. The surface urban energy and water balance scheme (SUEWS): Evaluation in Los Angeles and Vancouver. Journal of Hydrology, 411, pp. 219-237, 2011. DOI: 10.1016/j.jhydrol.2011.10.001.

[12] Szabo, S., Nicholls, R. \& Neumann, B. Making SDGs work for climate change hotspots. Environment: Science and Policy for Sustainable Development, 58(6), 24-33, 2016. DOI: 10.1080/00139157.2016.1209016.

[13] Lopes, M., Borrego, C., Martins, H. \& Amorim, J.H. Understanding Urban Metabolism: Guidelines for Urban Sustainable Development. New York: Routledge, pp. 197-205, 2014. 
[14] IPCC. Climate Change 2014: Synthesis Report. Contribution of Working Groups I, II and III to the Fifth Assessment Report of the Intergovernmental Panel on Climate Change, Geneva, Switzerland: IPCC, 2014.

[15] Rafael, S., Martins, H., Borrego, C. \& Lopes, M. Urban vulnerability and resilience to climate change. WIT Transactions on Ecology and the Environment, 198, pp. 379-390, 2015. DOI: 10.2495/AIR150331.

[16] IPCC. Climate Change 2013 - The Physical Science Basis. Contribution of Working Group I to the Fifth Assessment Report of the Intergovernmental Panel on Climate Change, Geneva, Switzerland: IPCC, 2013.

[17] Revi, A., et al. Urban areas. In: Climate Change 2014: Impacts, Adaptation, and Vulnerability. Part A: Global and Sectoral Aspects. Contribution of Working Group II to the Fifth Assessment Report of the Intergovernmental Panel on Climate Change, pp. 535-612, 2014.

[18] Chrysoulakis, N., de Castro, E.A. \& Moors, E.J. Understanding Urban Metabolism: A Tool for Urban Planning, New York: Routledge, 2014.

[19] Akbari, H., Menon, S. \& Rosenfeld, A. Global cooling: Increasing world-wide urban albedos to offset CO2. Climatic Change, 94, pp. 275-286, 2009. DOI: 10.1007/s10584008-9515-9.

[20] Wild, M., Ohmura, A. \& Cubasch, U. GCM-simulated surface energy fluxes in climate change experiments. Journal of Climate, 10, pp. 3093-3110, 1997. DOI: 10.1175/1520-0442(1997)010\&lt;3093:GSSEFI\&gt;2.0.CO;2.

[21] Sheng, L., Liu, S.H. \& Liu, H.P. Influences of climate change and its interannual variability on surface energy fluxes from 1948 to 2000. Advances in Atmospheric Sciences, 27, pp. 1438-1452, 2010. .DOI: 10.1007/s00376-010-9215-z.

[22] Ma, E., Deng, X., Zhang, Q. \& Liu, A. Spatial variation of surface energy fluxes due to land use changes across China. Energies, 7, pp. 2194-2206, 2014. DOI: 10.3390/ en7042194.

[23] Rafael, S., et al. Quantification and mapping of urban fluxes under climate change: Application of WRF-SUEWS model to Greater Porto area. Environmental Research, 155, pp.321-334, 2016. DOI: 10.1016/j.envres.2017.02.033.

[24] European Environment Agency (EEA). The European Environment: State and Outlook 2015: Synthesis, European Environment Agency, p. 42, 2015.

[25] Borrego, C., et al. Elaboração de Plano de Qualidade do Ar de Ozono da região Norte. Aveiro: Relatório 1 -Plano de trabalhos detalhado, 2014.

[26] Borrego, C., et al. Reducing $\mathrm{NO}_{2}$ pollution over urban areas: Air quality modelling as a fundamental management tool. Water Air and Soil Pollution, 223, pp. 5307-5320, 2012. DOI: $10.1007 / \mathrm{s} 11270-012-1281-7$.

[27] Borrego, C., Sa, E., Carvalho, A., Sousa, S. \& Miranda, A.I. Plans and programmes to improve air quality over Portugal: A numerical modelling approach. International Journal of Environment and Pollution, 48, pp. 60-68, 2012. DOI: 10.1504/ IJEP.2012.049652.

[28] Thambiran, T. \& Diab, R.D. A review of scientific linkages and interactions between climate change and air quality, with implications for air quality management in South Africa. South African Journal of Science, 106, pp. 20-27, 2010. DOI: 10.4102/sajs. v106i3/4.56.

[29] Elminir, H.K. Dependence of urban air pollutants on meteorology. Science of the Total Environment, 350, pp. 225-237, 2005. DOI: 10.1016/j.scitotenv.2005.01.043.

[30] Jacob, D.J. \& Winner, D.A. Effect of climate change on air quality. Atmospheric Environment, 43, pp. 51-63, 2009. DOI: 10.1016/j.atmosenv.2008.09.051. 
[31] Flaum, J.B., Rao, S.T. \& Zurbenko, I.G. Moderating the influence of meteorological conditions on ambient ozone concentrations. Journal of the Air \& Waste Management Association, 46, pp. 35-46, 1996. DOI: 10.1080/10473289.1996.10467439.

[32] Lacressonnière, G., et al. European air quality in the 2030s and 2050s: Impacts of global and regional emission trends and of climate change. Atmospheric Environment, 92, pp. 348-358, 2014. DOI: 10.1016/j.atmosenv.2014.04.033.

[33] Carvalho, A., Monteiro, A., Solman, S., Miranda, A.I. \& Borrego, C. Climate-driven changes in air quality over Europe by the end of the 21 st century, with special reference to Portugal. Environmental Science \& Policy, 13, pp. 445-458, 2010. DOI: 10.1016/j. envsci.2010.05.001.

[34] Sá, E., et al. Climate change and pollutant emissions impacts on air quality in 2050 over Portugal. Atmospheric Environment, 131, pp. 209-224, 2016. DOI: 10.1016/j. atmosenv.2016.01.040.

[35] Marta-Almeida, M., Teixeira, J.C., Carvalho, M.J., Melo-Gonçalves, P. \& Rocha, A.M. High resolution WRF climatic simulations for the Iberian Peninsula: Model validation. Physics and Chemistry of the Earth, 94, pp. 94-105, 2015. DOI: 10.1016/j.pce.2016.03.010.

[36] UNEP., IEA Training Manual Volume Two Themes: Vulnerability and Impact Assessment for Adaptation to Climate Change (VIA Module), Nairobi, Kenya: United Nations Environment Programme, 2010.

[37] Manders, A.M.M., et al. The impact of differences in large-scale circulation output from climate models on the regional modeling of ozone and PM. Atmospheric Chemistry and Physics, 12, pp. 9441-9458, 2012. DOI: 10.5194/acp-12-9441-2012-supplement.

[38] Zhang, Y., et al. Responses of future air quality to emission controls over North Carolina, part II: Analyses of future-year predictions and their policy implications. Atmospheric Environment, 44, pp. 2767-2779, 2010. DOI: 10.1016/j.atmosenv.2010.03.022.

[39] Blackman, K., Perret, L., Savory, E. \& Piquet, T. Field and wind tunnel modeling of an idealized street canyon flow. Atmospheric Environment, 106, pp. 139-153, 2015. DOI: 10.1016/j.atmosenv.2015.01.067.

[40] Masson, V., et al. The canopy and aerosol particles interactions in Toulouse urban layer (CAPITOUL) experiment. Meteorology and Atmospheric Physics, 102, pp. 135-157, 2008. DOI: 10.1007/s00703-008-0289-4.

[41] Efthimiou, G.C., Berbekar, E., Harms, F., Bartzis, J.G. \& Leitl, B. Prediction of high concentrations and concentration distribution of a continuous point source release in a semi-idealized urban canopy using CFD-RANS modeling. Atmospheric Environment, 100, pp. 48-56, 2015. DOI: 10.1016/j.atmosenv.2014.10.040.

[42] Lateb, M., et al. On the use of numerical modelling for near-field pollutant dispersion in urban environments - A review. International Journal of Environment and Pollution, 208, pp. 271-283, 2016. DOI: 10.1016/j.envpol.2015.07.039.

[43] Grimmond, C.S.B., et al. Meteorological and air quality models for urban areas. Meteorological and Air Quality Models for Urban Areas, 35, pp. 97-123, 2009. DOI: 10.1007/9783-642-00298-4_11.

[44] Grimmond, C.S.B., et al., Initial results from phase 2 of the international urban energy balance model comparison. International Journal of Climatology, 31, pp. 244-272, 2011. DOI: 10.1002/joc.2227.

[45] Pyles, R.D., Weare, B.C., Paw U, K.T. \& Gustafson, W., Coupling between the University of California, Davis, Advanced Canopy-Atmosphere-Soil Algorithm (ACASA) and MM5: Preliminary results for July 1998 for western North America. Journal of Applied Meteorology, 42, pp. 557-569, 2003. DOI: 10.1175/1520-0450(2003)042\&lt;0557:CB TUOC\&gt;2.0.CO;2. 
[46] Masson, V., A physically-based scheme for the urban energy budget in atmospheric models. Boundary-Layer Meteorology, 94, pp. 357-397, 2000. DOI: 10.1023/A: 1002463829265.

[47] Lohrey, S. \& Creutzig, F., A 'sustainability window'of urban form. Transportation Research Part D: Transport and Environment, 45, pp. 96-111, 2016. DOI: 10.1016/j. trd.2015.09.004.

[48] Slovic, A.D., de Oliveira, M.A., Biehl, J. \& Ribeiro, H., How can urban policies improve air quality and help mitigate global climate change: A systematic mapping review. Journal of Urban Health, 93, pp. 73-95, 2016. DOI: 10.1007/s11524-015-0007-8.

[49] Arneth, A., Unger, N., Kulmala, M. \& Andreae, M.O., Atmospheric science. Clean the air, heat the planet? Science, 326, pp. 672-673, 2009. DOI: 10.1126/science.1181568.

[50] Wang, Z.L., Zhang, H. \& Zhang, X.Y., Simultaneous reductions in emissions of black carbon and co-emitted species will weaken the aerosol net cooling effect. Atmospheric Chemistry and Physics, 15, pp. 3671-3685, 2015. DOI: 10.5194/acp-15-3671-2015.

[51] Maione, M. et al., Air quality and climate change: Designing new win-win policies for Europe. Environment: Science and Policy, 65, pp.48-57, 2016. DOI: 10.1016/j.envsci.2016.03.011.

[52] Andersson, C. \& Engardt, M., European ozone in a future climate: Importance of changes in dry deposition and isoprene emissions. Journal of Geophysical Research: Atmospheres, 115, D02303, 2010. DOI: 10.1029/2008JD011690.

[53] Bollen, J., van der Zwaan, B., Brink, C. \& Eerens, H., Local air pollution and global climate change: A combined cost-benefit analysis. Resource and Energy Economics, 31, pp. 161-181, 2009. DOI: 10.1016/j.reseneeco.2009.03.001.

[54] Nemet, G.F., Holloway, T. \& Meier, P., Implications of incorporating air-quality cobenefits into climate change policymaking. Environmental Research Letters, 5, p. 14007, 2010. DOI: $10.1088 / 1748-9326 / 5 / 1 / 014007$.

[55] Stohl, A. et al., Evaluating the climate and air quality impacts of short-lived pollutants. Atmospheric Chemistry and Physics, 15, pp. 10529-10566, 2015. DOI: 10.5194/acp-1510529-2015.

[56] EU., Towards an EU Research and Innovation Policy Agenda for Nature-Based Solutions \& Re-Naturing Cities - Final Report of the Horizon 2020 Expert Group on 'Nature-Based Solutions \& Re-Naturing Cities'. Brussels, Belgium: Publications Office of the European Union, 2015.

[57] Oke, T.R. Initial guidance to obtain representative meteorological observations at urban sites. World Meteorological Organization, WMO/TD1250, p. 51, 2006.

[58] Toparlar, Y. et al. CFD simulation and validation of urban microclimate: A case study for Bergpolder Zuid, Rotterdam. Building and Environment, 83, pp.79-90, 2015. DOI: 10.1016/j.buildenv.2014.08.004.

[59] Wu, X., Zou, X., Zhou, N., Zhang, C. \& Shi, S. Deceleration efficiencies of shrub windbreaks in a wind tunnel. Aeolian Research, 16, pp. 11-23, 2015. DOI: 10.1016/j. aeolia.2014.10.004.

[60] Carvalho, D., Martins, H., Marta-Almeida, M., Rocha, A. \& Borrego, C. Urban resilience to future urban heat waves under a climate change scenario: A case study for Porto urban area (Portugal). Urban Climate, 19, pp.1-27, 2016. DOI: 10.1016/j.uclim.2016.11.005. 